\title{
Sem fins lucrativos. Por que a democracia precisa das humanidades Martha Nussbaum
}

\author{
Martins Fontes, São Paulo, 2015, 153 págs. \\ Ecila Moreira de Meneses \\ E-mail: ecilameneses@yahoo.com.br

\section{Fernando de la Cuadra} \\ E-mail: fmdelacuadra@gmail.com
}

Recentemente uma proposta realizada pelo Ministro de Educação, Cultura, Esportes, Ciência e Tecnologia do Japão, Hakubun Shimomura, gerou incredulidade entre académicos, intelectuais, artistas, políticos e especialistas no âmbitodo ensino superior nesse país como no resto do planeta.A proposta do ministro consistia em eliminar os cursos de humanidades e artes para centrar a formação universitária em cursos mais técnicos, visando melhorar o desempenho econômico de Japão em crise de estagnação durante asduas últimas décadas. No documento ele solicitava avançar com passo decidido para uma abolição de tais matérias ou transforma-las para "servir em outras áreas que atendam melhor as necessidades da sociedade". Oreferido anuncio teve uma boa acolhida dentre 26 das 86 universidades estatais, algumas das quais já tinham eliminado o ingresso de estudantes a cursos de humanidades. A exemplo do Japão outros países têm-se entusiasmado como esta ideia de transformar, diminuir ou simplesmente eliminar a educaçãoe a pesquisa em humanidades eciências sociais.

Enfrentando ditatendência, a filosofa norte-americana Martha Nussbaum publicou um livro cujo título representa uma feliz síntese de seu apelo em torno à defesa das humanidades como elemento essencial para a construção de uma sociedade democrática. Nosuscinto e contundente "Sem fins lucrativos", a professora da Universidade de Chicago discorre sobre o fato de que aquilo que está em risco no mundo contemporâneo não reside somente no descalabro económico da atual conjuntura e sim muito mais naquilo que desde uma perspectiva de longo prazo é muito mais grave e que passa desapercebida para muitas pessoas e instituições: a crise mundial da educação.

Nele, Martha Nussbaum traz uma discussão sobre uma questão que sendo central é permanentemente relegada a um plano secundário: a importância das humanidades e das artes, de como elas conectam-se num horizonte mais vasto com a pedagogia, ínsita a política e a vida social 
compartilhada, solidária, eticamente fundada. Mas, o que Nussbaum vai destacar é a necessidade de se levar para dentro dos currículos escolares e, em especial, para os currículos acadêmicos, o estudo das ciências humanas e das artes liberais, como forma de se construir uma sociedade democrática, e é o que indica o próprio subtítulo do livro: "Por que a democracia precisa das humanidades".

Nesse sentido, a principal preocupação da pensadora é entender por quê as competênciasque são tão decisivas para a manutenção e consolidação de qualquer democracia sejam obliteradas pela preferência daquelas disciplinas cuja finalidade consiste na obtenção de maiores lucros por parte das empresas. Desta forma, ela adverte que os reitores promovem semináriose eventos que se orientam a melhorar a oferta de negócios da universidade, mas que demonstram muito pouco interesse por temáticas humanistas que possuiriam um baixo impacto para as empresas e entidades financiadoras.

Em sua obra, a filósofa defende acima de tudo, valores humanistas e argumenta em prol de uma educação que tenha como objetivo principal formar cidadãos universais e não formar pessoas convenientes para o mercado. Dentro de uma tradição liberal clássica, no sentido da defesa das liberdades políticas, e mais ainda, dentro de um liberalismo social, Nussbaum dialoga com pensadores como John Dewey, Jean-Jacques Rousseau, Donald Winnicott, Ralph Ellison e Rabindranath Tagore, revelando o pluralismo de suas referências. O livro critica a cultura da competitividade e do progresso pessoal como uma visão que gera indivíduos egocêntricos e ensimesmados, de tal forma a incapacitá-los para a compreensão e a sensibilidade de valores éticos fundantes da civilidade e para a construção de uma sociedade democrática.

No capítulo: “Educação Para o Lucro, Educação Para a Democracia”, a autora advoga pelo Paradigma do Desenvolvimento Humano que é um projeto de crescimento onde o importante são as oportunidades dadas ao cidadão. Este deve ter condições para o seu desenvolvimento dentro de um referencial de dignidade humana, e de desenvolvimento dos valores da autonomia individual e social. Mas, para que isto aconteça é fundamental estabelecer uma relação dialogal entre os governos e o povo, e o estabelecimento de um espaço comum de encontro dos cidadãos, para além do recôndito de suas vidas privadas. E como na Democracia Ateniense, os cidadãos de hoje também precisam de uma educação ampla, ecumênica, para pensar e, posteriormente, para argumentar. É necessário capacitar os indivíduos para raciocinar temas políticos, sem restringir-se, apenas aos aspectos técnicos dos problemas.

Outro aspecto a ser devidamente sublinhado é a percepção de que a democracia é feita por pessoas comuns, no âmbito do cotidiano e em seus variados espaços e demandas. Também devemos vivenciar processos democráticos na esfera das instituições jurídicas e políticas, inclusive na capacidade de entabularmos críticas aos nossos líderes políticos do Estado. Mesmo porque a nação não pode mais ser vista como expressão abstrata 
de um todo indiviso, mas como um todo composto de variados grupos, de processos contraditórios, formados pela mediação de plexos de sensibilidades e interesses. Enfim, para compreender que o seu país é apenas mais um país dentro de um enorme mundo com vários outros países, povos e culturas diferentes da sua.

Existe um modelo de formação que é fundamental para construir os alicerces da democracia. Esse modelo consiste no aprendizado que implica a participação ativa dos alunos a través de perguntas e questionamentos. Esta perspectiva pedagógica supõe que os alunos não precisam aguardar passivamente os conteúdos que são ministrados pelos professores, mas pelo contrário, supõe que existe um trabalho em conjunto para resolver as interrogantes colocadas na sala de aula. Diferentemente, o sistema imperante deseja contar com grupos de aprendizagem que posteriormente funcionem como operários disciplinados e obedientes, sem capacidade de raciocínio crítico e assim destinados a executar exclusivamente as tarefas que lhe são encomendadas segundo os interesses do capital e das empresas.

Depois das conquistas do Estado Social, tivemos uma nova investida dos capitalistas com a prioridade de investimentos no mercado financeiro e não mais no mercado produtivo de bens. O modelo de crescimento econômico desconectado da igualdade distributiva e social, de uma democracia estável e da boa qualidade nas relações raciais e de gênero, passou a imperar em vários países. Mas, para a efetivação deste modelo é preciso formar profissionais que sejam preparados para atuar neste novo mercado. $\mathrm{O}$ que tivemos como consequência nos currículos acadêmicos foi a superação de uma cultura de formação mais ampla e plural para a conformação de um profissional apto para atender as necessidades deste mercado financeiro. A visão tecnocrática e privatista vai excluindo as disciplinas das ciências humanas e o contato com as artes, muito bem abordado no capítulo "Crise Silenciosa”.

Desta maneira, salienta Nussbaum, a educação para o crescimento económico ou educação para a renda despreza a formação em disciplinas como as artes e a literatura, pois considera que elas não conduzem nem ao progresso das pessoas nem menos ao progresso da economia nacional. Por esse motivo, no mundo inteiro "os cursos de artes e humanidades estão sendo eliminados de todos os níveis curriculares, em favor do desenvolvimento dos cursos técnicos”. (p. 23). Estas mudanças que vem ocorrendo em escala global representam uma ameaça para a vida democrática, na medida em que descartam sem cogitação aqueles rasgos das humanidades que são essenciais para a convivência democrática. Preocupada com esta orientação que vem adquirindo os rumos da educação no mundo e no seu próprio país, ela transforma sua reflexão num veemente manifesto contra os obstáculos que se pretendem impor às artes e às humanidades, fazendo recortes orçamentários ou realocando os recursos para aquelas disciplinas consideradas com maior retorno económico, como as ciências naturais, as matemáticas ou as tecnologias. 
A crítica que a autora faz aos currículos excessivamente tecnológicos vai para além dos cursos acadêmicos das áreas de humanas. Tais aspectos essenciais na formação da cidadania, diz respeito à principialidade ética dos fins de uma sociedade democrática, incluindo, os propósitos a que os profissionais devem estar afetos. Para ela, não importa se o estudante é da engenharia, da saúde, das áreas tecnológicas, da matemática, física, botânica ou etc., todos, invariavelmente todos, deveriam passar por um currículo onde as ciências humanas e as artes estariam incluídas como disciplinas necessárias, e não só opcionais. Mas, não só, Martha Nussbaum argumenta também em defesa de uma metodologia socrática, questionadora e dialogal, onde o exercício permanente e profundo da argumentação serviria de experiência viva e concreta para a internalização de uma postura democrática e civilizada.

A ausência de uma concepção humanista na qual enxergamos a importância da diferença com os Outros condenaria aos seres humanos a conceber um mundo estreito regido por interesses utilitaristas e manipuladores, onde o restante das pessoas são percebidas como entes inanimados dos quais se pode usufruir qualquer tipo de ganancia. Neste cenário a democracia encontra-se fadada ao fracasso porque contrariamente aos pressupostos da corrente individualista e concorrencial, ela baseia-sena dignidade e na consideração da alteridade, na capacidade de perceber os outros seres humanos como sujeitos de respeito e não como simples objetos.

Afinal, o reconhecimento do outro e a construção da democracia, requer a percepção da intersubjetividade dos vínculos, das outras pessoas como detentoras de direitos e da ação criadora da política. Posto que, para entender a política democrática faz-se importante, abrir-se para as diferenças, como momento qualificado para conhecer visões e experiência distintas que trarão também outras soluções, perspectivas diferentes de mundo, consumando assim, a alteridade indispensável para a conformação de uma totalidade institucional rica.

Num mundo cada vez mais pautado pela aquisição de maior lucro e riqueza, Martha Nussbaum está abocada em demonstrar como as humanidades e as artes desempenham um papel decisivo na formação de cidadãos que tenham um olhar amplo e complexo da sociedade para pensar criticamente as questões mais prementes que surgem em nossa convivência comum. Portanto, para ter a capacidade de compreender empaticamente a experiência de vida e o sofrimento dos Outros.

Pelo mesmo, outra questão importantíssima tratada pela autora é a capacidade dialogal. Este tema é abordado no capítulo "Pedagogia Socrática: a Importância da Argumentação”. Aqui a filosofia e a maiêutica são fundamentais para o exercício do pensamento democrático. Para sustentar sua defesa dos cursos de filosofia e humanidades, a autora recorre a Sócrates e seu ideal, no qual os indivíduos aprendem a capacidade e a autonomia para pensar e argumentar por si mesmos em vez de se submeter passivamente 
à tradição e à autoridade como ferramenta para entender o mundo. Se o foco não se encontra na argumentação as pessoas podem ser levadas a tomar decisões a partir do peso da tradição ou pelo prestigio cultural do orador.

É na nossa argumentação e no confronto com o argumento do outro que nós descobrimos, aprofundamos nossos pensamentos, percebemos nossas contradições e aprendemos novas possibilidades de percepção da realidade e de como lidar com os problemas. Nos dias de hoje, cada vez mais temos sociedades onde existem a convivência de pessoas de religiões e de etnias diferentes. O pensamento socrático traz a responsabilidade do próprio raciocínio, como também, traz o respeito ao pensamento do outro. É como diz a própria professora Nussbaum: Na crítica socrática "a posição social do orador não conta; a única coisa que conta é a natureza da argumentação (...) Em uma democracia, a pessoa adequada para se ter é aquela que está preparada para acompanhar uma argumentação em vez de números, o tipo de pessoa que enfrentaria a pressão para que dissesse algo falso ou precipitado”. (pp. 50-51). Pelo mesmo é fundamental estimular a formação do pensamento de cada um, e não a repetição de uma ideia de um grupo que pressiona você. "O argumentador socrático é um dissidente inveterado porque sabe que a única coisa que existe é cada um com sua argumentação a lidar com as coisas”. (p. 51).

Daí a importância do debate democrático nas escolas e nas universidades como forma de superar a perspectiva de que a educação deve estar colocada principalmente ao serviço do crescimento econômico e do quantitativo. Além disso, o verdadeiro debate democrático permite perceber os outros como uma alteridade, como parte de uma disputa em que o ganhador não deve necessariamente destruir ou humilhar o adversário, que não é um inimigo. Nessa trilha, Nussbaum vai expondo um conjunto de autores (Johann Pestalozzi, Friedrich Froebel, Bronson Alcott, Horace Mann, John Dewey e Rabindranath Tagore) que recuperam a herança socrática com um modelo educativo intimamente ligado a uma concepção igualitária e inclusiva de democracia. Através de um intenso percurso histórico, a autora nos revela esta tradição assentada em valores socráticos que configuram as características de um tipo de cidadão formado para a democracia: atuante, crítico, curioso, capaz de resistir à autoridade e à pressão dos iguais.

Certamente a educação para uma cidadania global representa uma temática bastante complicada, mas a filósofa estadunidense acredita que ela é fatível quando existe um currículo no qual um conjunto de disciplinas como história, geografia, sociologia, estudos culturais, religião, estudos políticos e de filosofia do direito ministradas de maneira articulada (educação interdisciplinar) possam contribuir efetivamente para o desenvolvimento de um olhar abrangente e pluralista por parte dos alunos. Embora não se possa formar pessoas que resistam permanentemente às formas de autoritarismo e discriminação, sim é possível criar uma cultura social mais democrática e solidaria. Nesse sentido, por exemplo, a escola pode desenvolver a capacidade dos alunos de observar o mundo desde o ponto de vista dos outros, especialmente daquelas pessoas cujas sociedades tendem a consi- 
derar-se como inferiores e, portanto, coisificadose tratados como meros objetos.

A formação de uma cidadania responsável requer também do cultivo da imaginação por meio da literatura e das artes. Quer dizer, em sociedades complexas os cidadãos não somente devem ser iniciados numa leitura do mundo através do uso do conhecimento fatual e da lógica. Eles também precisam incorporar aquilo que a autora denomina como "imaginação narrativa”. Nas suas palavras:

“Isso significa a capacidade de pensar como deve ser se encontrar no lugar de uma pessoa diferente de nós, de ser um interprete inteligente da história dessa pessoa e de compreender as emoções, os anseios e os desejos que alguém naquela situação pode ter”. (pp. 95-96).

Neste processo a literatura e as artes desempenham um papel fundamental na medida em que ambas disciplinas permitem que as pessoas observem o mundo desde a perspectiva dos outros. Apesar de que este não é um dever exclusivo das escolas e das universidades, no entanto são elas as principais entidades chamadas a desenvolver um tipo de formação voltada para estimular as capacidades e vocações críticas dos discentes e que aprimora também seus recursos cognitivos para que possam situar-se e perceber o mundo através do olhar dos outros, ou seja, para experimentar profundamente aquilo que se conhece como alteridade. Perante a pergunta sobre como está se saindo a educação para a cidadania democrática no mundo de hoje, a autora responde negativamente, o qual não deixa de constituir uma conclusão previsível a partir do próprio desenvolvimento desteensaio. No entanto, ela pretende que seu manifesto por uma formação humanista se transforme numa interpelação para agir e não ficar observando passivamente como a realidade funciona: "Caso se chegue à conclusão de que as coisas estão menos ruins do que acredito que estejam, isso não é motivo para respirar aliviado (...) Devemos redobrar nosso compromisso com os elementos da educação que mantem a vitalidade da democracia”. (p. 122).

Lamentavelmente, insiste Nussbaum, o mundo parece orientar-se decididamente para a consolidação de um sistema em que a formação de pessoas que ofereçam um produto com impacto e que gere lucros interessa muito mais que a formação de cidadãos preocupados pela cidadania democrática e pelo reconhecimento e o respeito dos outros como prática quotidiana.

A reforma do ensino médio que atualmente está sendo implementada no Brasil, incorpora precisamente mudanças que visam eliminar a obrigatoriedade de disciplinas como História, Geografia, Sociologia ouFilosofia sob a alegação de que os alunos somente precisam como cursos obrigatórios a Matemática e o Português. Tais mudanças não são somente decorrência dos problemas econômicose orçamentáriosque en- 
frenta o país atualmente, mas sobretudo são consequênciade uma postura ideológica retrograda, que considera às humanidades e às artes não somente como disciplinas supérfluas, mas fundamentalmente como doutrinas perigosas pelo grau de reflexão crítica (subversiva neste caso) que elas trazem para o conjunto da sociedade. Num período em que Brasil enfrenta um processo de retrocesso político e cultural, a ameaça do obscurantismo pedagógico se disfarça com o discurso de que os alunos devem privilegiar disciplinas técnicas que lhes permitam incorporar-se como força de trabalho qualificada. Nesse contexto sombrio e conservador, a reflexão de Martha Nussbaum adquire mais do que nunca sua plena vigência e pertinência.

"Se não insistirmos na importância crucial das humanidades e das artes, elas vão desaparecer gradativamente porque não dão lucro. Elas só fazem o que é muito mais precioso do que isso: criam um mundo no qual vale a pena viver, pessoas que são capazes de enxergar os outros seres humanos como pessoas completas, com opiniões e sentimentos próprios que merecem respeito e compreensão, e nações que são capazes de superar o medo e a desconfiança em prol de um debate gratificante e sensato”. (pp. 143-144).

Certamente, especialistas em educação, em temáticas de cidadania e de política democrática não encontraram nas páginas deste ensaio ideias extremamente originais, mas a força e a paixão com a qual se expressa esta provocativa pensadora representam indubitavelmente um manifesto para agir nas sinuosidades da realidade contemporâneae para pensar que outro mundo é possível. 